\title{
Belisário Penna, Combatente: um capítulo da história da saúde pública brasileira'
} \author{
Belisário Penna, a champion in the history of Brazilian Public
} Health

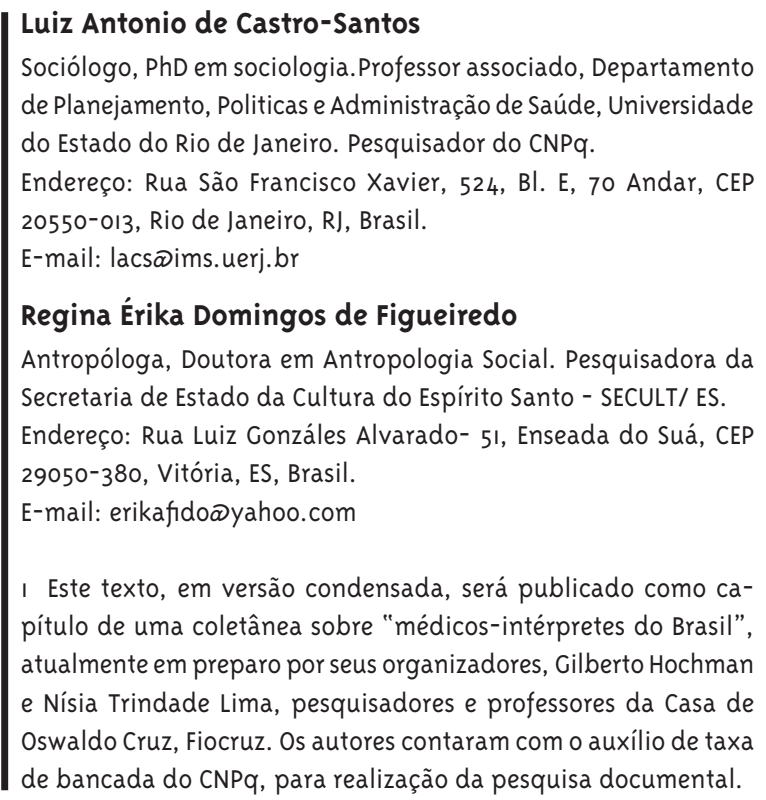

\section{Resumo}

A contribuição do médico sanitarista Belisário Penna (1868-1939) à história da saúde pública no Brasil constitui o tema central do texto. Belisário Penna é retratado aqui a partir de sua militância, dos combates que travou em defesa do saneamento rural e pela melhoria das condições de saúde de toda a população brasileira. 0 propósito também é situá-lo em meio aos debates de sua época, esclarecendo, por exemplo, como as ideias de Belisário - tão bem apresentadas em suas eloquentes palestras - primavam por se contrapor ao pensamento racista dominante entre as elites do País. Belisário argumentava que os obstáculos ao progresso nacional residiam na precariedade tanto da saúde quanto da instrução pública. Nessa medida, os problemas referidos à questão da eugenia no País eram interpretados sob um prisma otimista: no lugar de determinismos raciais intangíveis, a presença do Estado, por meio de programas de higiene e educação cívica, traria o progresso desejado. O "otimismo sanitário" do combatente mineiro não consistiu em um atributo só dele, mas era compartilhado por outros médicos e intelectuais em torno de movimentos como a Liga Pró-Saneamento, cujas bandeiras acenavam a necessidade de mudanças sociais e alcançaram significativa ressonância popular.

Palavras-chave: Belisário Penna; Saúde pública; Questão racial; Eugenia. 


\section{Abstract}

The contribution of the sanitarian Belisário Penna (1868-1939) to the history of public health in Brazil constitutes the central topic of this text. The intellectual, professional, and political profile of Belisário Penna is here reconsidered, in the light of his entrenched defense of rural sanitation, his militancy in favor of the improvement of living conditions in the backlands of Brazil, and his criticism of oligarchical power. The intention is also to point out how he opposed, through a series of speeches of great eloquence, the climate of opinion in Brazil's early Republic. He took in the preoccupations of Brazilian elite with "eugenics," discussing them in a very different, optimistic vein. Belisário Penna opposed the dominant racist thought among the aristocracy of the country, arguing that the real obstacles to the national progress resided in the precariousness of health conditions as much as in the lack of public education. In this sense, Belisário was at the forefront of the intellectual and political circles that supported a determined action of the State, by means of hygiene and civic education programs. Better health, these progressive circles insisted, would bring a solution to the alleged racial "inferiority" of Brazilians. This kind of "sanitary optimism" was not shared by only a few progressive minds, but was the core of social movements such as the Pro-Sanitation League of Brazil, which gathered doctors and intellectuals. These movements propagated the need for social change and received considerable support of the public opinion in the 1920's.

Keywords: Belisário Penna; Public Health; Racial Question; Eugenics.

\section{À memória de Moacyr Scliar}

"Uma fogueira de palavras irrompe na praça" Lêdo Ivo

Um dos expoentes da saúde pública no Brasil tornouse famoso, em sua época, pelos incontáveis sucessos de sua oratória: palavra fácil, ideias em erupção, figura de grande carisma, próximo aos donos do poder, mas de imensa capacidade de comunicação com as pessoas do povo. Belisário Augusto de Oliveira Penna, mineiro de Barbacena (1868-1939), construiu um perfil de sanitarista de primeira linha durante o primeiro período republicano; mobilizou a opinião pública, organizou movimentos em defesa da saúde pública e foi incansável desde os tempos de moço até já idoso, quando ocupou postos importantes na Saúde Pública federal, no início da "Era Vargas".

Seus pais batizaram-no Belisário, antecipando para o filho a carreira fulgurante do General Belisarius, bravo chefe dos exércitos do Império Bizantino. Nosso Belisário por certo não desapontou seus pais, sua geração e as que se seguiram. Dotado da inteligência ágil e do carisma de um líder, tais qualidades o colocaram, sem favor, no rol dos grandes nomes da luta pela Reforma Sanitária e pela Educação Pública, em seus primeiros e heroicos tempos de produção de "utopias de Brasil", para lembrar a expressão feliz de Sarah Escorel.

Um pequeno livro, escrito pelo emérito Prof. Carlos da Silva Lacaz sobre os grandes nomes da medicina brasileira, traz uma curta biografia sobre nosso ilustre sanitarista. Formou-se pela Faculdade de Medicina da Bahia, em 189o. Aprovado em concurso público, foi nomeado Inspetor Sanitário do governo federal e designado para as campanhas de profilaxia da febre amarela no Distrito Federal, em 1905. Um convite de Oswaldo Cruz deslocou-o para a Amazônia. No Pará, empenhou-se na luta antiamarílica. Isto foi em 1911 e pode-se dizer que este contato com populações longínquas e abandonadas abriu-lhe as portas para uma militância que jamais abandonaria.

Partiram desde então, de Manguinhos, as bandeiras rumo ao grande Sertão, chefiadas por Belisário e por tantos outros, dotados de igual fervor missionário pela ciência, pela nação e pela saúde das populações. Entre março e outubro de 1912, uma 
expedição científica ao norte e nordeste, capitaneada por Belisário Penna e Arthur Neiva (este, um eminente pesquisador), tornou-se logo um emblema dos esforços de construção nacional e integração territorial que caracterizaram o primeiro período republicano.

Nos anos seguintes, Belisário ergueu mais alto a bandeira do saneamento rural, dedicando-se à intensa pregação sobre os temas da higiene, que culminou com sua proposta de criação da Liga Pró-Saneamento do Brasil. Em resumo, os esforços desse combatente foram bem-sucedidos: de um lado, numerosos postos de profilaxia rural foram abertos em várias regiões do País; de outro lado, e também sob sua inspiração, o papel do Estado na saúde ampliou-se com a criação do Departamento Nacional de Saúde Pública, uma espécie de balão de ensaio de um órgão ministerial, que seria criado uma década mais tarde, durante o regime de Vargas (Figueiredo, 2007).

Fizemos referência às posições de destaque de Belisário Penna, na saúde pública, desde o início do período varguista, que encerrava o período conhecido como a Primeira República. Ainda nos primeiros anos do Governo Provisório de Getúlio Vargas, assumiu a direção do Departamento Nacional de Saúde Pública, órgão de forte tradição desde a década de 1920. Em 1932, subordinado ao recém-criado Ministério da Educação e Saúde Pública, o Departamento perderia em boa medida o antigo impacto político e simbólico em defesa das populações rurais. Em parte por desavenças com os novos próceres da saúde, em parte por adesão ao ideário protofascista do integralismo, Belisário deixou a política oficial e, até sua morte, em 1939, aderiu à ação integralista, voltada para a intensa mobilização e politização das massas. Mas note-se: na política nacional, foram as bandeiras de ação programática pela saúde que constituíram seu legado, não sua opção pelo ideário integralista, já ao fim da vida.

Os leitores não familiarizados com a projeção pública que Belisário Penna veio a conquistar em seu tempo terão também a oportunidade de recorrer ao livro de memórias do escritor Pedro Nava, que descreveu e interpretou como ninguém as relações entre política e memória nacional. Em Baú de Ossos (Nava, 1983), mostra-nos o perfil de Belisário como lutador incansável e politicamente lúcido, na defesa da saúde e da instrução pública. A militância de Belisário pela saúde foi também destacada por historiadores e cientistas sociais contemporâneos, a exemplo de Castro Santos (1985, 2008, Hochman (1998, 2002), Lima (1999, 2009) e Sá (2009); já sua participação exemplar no campo da educação pública, em especial sua contribuição ao projeto e às realizações da Associação Brasileira de Educação, foi abordada em estudo de Carvalho (1998). Mas não podemos deixar de citar um trecho da obra de Pedro Nava, por seu caráter informativo, dosado pelo necessário cuidado em não "imortalizar" ou beatificar os personagens de seu baú de memórias:

Não se sabia onde acabava o apóstolo e começava o charlatão; onde terminava o higienista e principiava o caixeiro-viajante do vermífugo, naquela bolinha humana de largura igual à altura que percorreu o Brasil como uma espécie de pregador, de mestre, de camelô, de messias, de orador popular, de empresário e redentor - falando a crianças, a adultos, a velhos; discursando nos grupos escolares, nos ginásios, nas faculdades, nas ruas, nos cinemas [...]; orando a analfabetos e a homens cultos; ao povo e aos políticos; a governados e governantes; nas fazendas, nas cidades; no Norte e no Sul - ensinando seu Evangelho: 'botina, Necatorina e latrina!' [...] Buraco no chão, fossa sanitária, latrina, só latrina (Nava, 1983, p. 302-303).

Os tempos retratados por Nava são os do início da República, sobretudo algumas décadas após a Proclamação. Muito se tem escrito sobre a importância que detinha, para as elites da época, a questão da eugenia, uma espécie de bandeira de salvação nacional para os males de nosso atraso em relação aos povos "mais adiantados", "mais civilizados" etc. Dificilmente se encontraria, naqueles dias, algum homem público que não defendesse o aperfeiçoamento de nossa "raça" por misturas bem proporcionadas, visando à melhoria e purificação de nosso capital humano - para usar os termos de hoje, cada vez mais em moda na Europa do terceiro milênio, "racialista" ou abertamente racista. A noção de uma miscigenação bem dosada, em particular pela entrada no Brasil do estoque imigratório europeu, era compartilhada por todos. Nessa preocupação comum com as "potencialidades eugenísticas" dos 
tipos regionais brasileiros e seu "apuramento racial" abriam-se pontos de discordância. É difícil demarcar os grupos de referência, uma espécie de "quem é quem" no mundo provinciano de então, que apresentava rachaduras, posições discordantes, ideologias contrastantes. Mas é possível sugerir que o divisor de águas estava na avaliação das possibilidades de aprimoramento da raça: para uns, diminuta, em face de um passado de miscigenação negativa com o negro e o índio, particularmente com o primeiro; para outros, apresentavam-se possibilidades consideráveis, se - o condicional era importante - a saúde das populações fosse aprimorada. Aqui se identificará a posição inequívoca de Belisário. Na linha de frente de intelectuais e homens públicos, deplorava, em conferência pronunciada em 1918, a "vergonhosa decadência de nossa gente de trabalho"; pregava a necessidade de os governos espalharem, pelos sertões do vasto território, "postos e mais postos sanitários", "verdadeiras escolas de educação higiênica”, "forjas da saúde”, "fundamentos da defesa nacional" (Penna, 1918b).

Por outro lado, não se equivocará quem aquilatar a força, no meio cultural e político da época, da corrente da desesperança no progresso nacional, diante da situação "eugênica” desfavorável do passado colonial e monárquico. O ensaísta Vianna Moog, em livro clássico sobre os contrastes entre Brasil e Estados Unidos, Bandeirantes e pioneiros, descreveu uma das matrizes daquela desesperança (Vianna Moog, 1964). O autor refere-se a Joaquim Murtinho, pertencente a uma importante oligarquia mato-grossense: médico homeopata respeitado na capital federal, economista por duas vezes ministro, da Viação, no governo de Prudente de Morais, e da Fazenda, no governo de Campos Salles, Murtinho era considerado por seus contemporâneos uma das maiores fortunas da República, no controle acionário da Companhia Mate Laranjeira, em seu Estado natal. As limitações históricas do País, em decorrência da inferioridade do estoque racial, mereceram destaque em seu relatório ministerial de 1897. Dizia o Ministro Murtinho: "Não podemos, como muitos aspiram, tomar os Estados Unidos da América do Norte como tipo para nosso desenvolvimento industrial, porque não temos as aptidões superiores de sua raça" (nosso grifo, citado em Vianna Moog, 1964, p. 6).
Não cabem ilusões. Na contracorrente das ideologias por assim dizer "terminais", sobre a nação, o otimismo sanitário de Belisário Penna era partilhado por um reduzido grupo de missionários, que abrigavam uma visão redentora do atraso e um projeto de construção nacional por meio da saúde e da educação. Esses poucos, embora muito atuantes em uma profusão de ligas e movimentos associativos, particularmente após os anos da primeira guerra mundial, encontravam a oposição de uma espécie de massa inercial poderosa, resultante de uma tradição de descrença que remontava às elites do Império.

Desde o período monárquico, as elites nacionais estavam sediadas na capital federal e ocupavam-se - verbo temido por quem de fato buscava sempre o ócio e a renda sem trabalho - em seus órgãos e aparatos institucionais, em suas casas de exportação de café e casas bancárias; seus pontos de encontro e de vida mundana eram as camisarias, cafés, "leiterias" e confeitarias, livrarias, oficinas e sedes da grande imprensa. Mas havia outros ritos consagrados de sociabilidade e difusão de valores e atitudes entre aristocratas e burgueses: entre esses, sobressaíam os que ocorriam por ocasião de falecimentos, por meio de expedientes, cerimoniais de luto e cultos que atendiam de modo flagrante aos requisitos de fortalecimento de laços de classe e status e demarcação de lealdades quase tribais. Muito mais marcantes do que nos tempos de hoje, esses rituais de classe compreendiam cartões de pêsames e a presença maciça nos sepultamentos e nas missas de sétimo dia. Se nos referimos a tais ritos, é porque as tradições, atitudes e representações grupais, as questões de classe e de status mais candentes, eram retomadas e como que cristalizadas em tais cerimônias e encontros. Ao nos reportarmos aos valores defendidos pelo Ministro Murtinho sobre as aptidões "inferiores" da raça, pode-se inferir o poder de tais tradições sobre as camadas mais influentes das elites, preservadas no dia a dia pelas figuras-chave da época.

A propósito, quando faleceu uma sobrinha de Murtinho, ainda muito jovem e por complicações de parto, a cidade assistiu, em 1918, meses antes da devastação da gripe "espanhola", a um ritual de congraçamento da elite carioca que merece breve referência: à missa de sétimo dia compareceram e assinaram o livro de registro pessoas que ocupavam 
o ápice da elite de poder. Eram barões e baronesas (bem à vontade na nova República), dignitários republicanos da Câmara e do Senado, figurões de Ministérios, Inspetorias e casas comerciais, entre centenas de outros nomes de destaque na sociedade e na política da época. As famílias de luto recebiam requintados cartões de pêsames, que à época eram preenchidos e assinados à mão; os pêsames pela morte da jovem Murtinho chegaram a quase mil, sobrenomes e endereços aristocráticos, preenchidos com clareza, para serem lidos, comentados e preservados. Eram rituais de fortalecimento de uma tradição que, ao mesmo tempo, solidificava os laços de lealdade intraelite (fonte: documentos de família).

Esse relato sobre um cerimonial de elite na capital federal seria absolutamente irrelevante, não fosse ele revelador do modo pelo qual se reproduziam e circulavam as novas/velhas ideias no mundo estreito e provinciano da Belle Époque tropical. A cultura de elite propagava-se por força de práticas ritualizadas como a que relatamos. Esses rituais podiam, desse modo, desempenhar a função de resistência a novos valores, como dispositivos de reprodução das tradições e ideologias enquistadas no tecido social.

Mas, como se difundiam os novos valores? Imagine-se a comoção causada pela morte de Oswaldo Cruz, meses antes, no verão de 1917, e os cerimoniais de consagração que se seguiram. Esses seriam, sem dúvida, rituais de mudança cultural - promovidos pelo "grupo de referência" de Oswaldo, íntimos amigos como Carlos Chagas e Salles Guerra, cientistas de Manguinhos, e por nosso Belisário! É como se a cidade "pranteasse seu morto ilustre", mas havia um sentido subjacente em tais eventos: Oswaldo Cruz e Belisário eram protagonistas de outro cenário e divulgadores de nova mentalidade sobre a eugenia no trópico brasileiro. Prantear Oswaldo era saudar novos valores. Nossos cruzamentos raciais, até então e por muito tempo malditos do ponto de vista da formação nacional, situavam-se, pouco a pouco, como um elemento positivo para a "civilização brasileira”. Mas, note-se, eram a saúde e a educação das populações brasileiras que serviriam de caução para o progresso da raça e para a reconfiguração da antiga "questão da eugenia". Belisário Penna era partícipe dessas correntes ainda inexpressivas nu- mericamente, mas, de todos os modos, impactantes na cultura de elite.

Ora, para alcançar alguma resistência às tradições mais arraigadas, fazia-se necessário, aos protagonistas da reforma da saúde e da educação, que os rituais de sociabilidade da jovem república alcançassem alguma mobilização popular. Os funerais de figuras importantes, como Oswaldo Cruz, não poderiam ater-se apenas à consagração pelos pares; teriam de se estender para fora dos limites de classe. Os rituais fúnebres em torno da morte de Oswaldo - como de Carlos Chagas, em 1934 e do próprio Belisário, em 1939 -, tiveram esse sentido subjacente, de preparação para um novo cenário. Lembremo-nos da caracterização de Pedro Nava sobre o "caixeiro-viajante" Belisário Penna, cujas palestras e conferências Brasil afora tinham esse sentido simbólico. As cruzadas do sanitarista tiveram um desaguadouro natural na criação de associações ou movimentos sociais de alcance popular - a exemplo da Liga Pró-Saneamento, apregoada por Belisário em sua conferência de Juiz de Fora, já em meados de 1918 (Penna, 1918b). O que se passava em Minas Gerais, a partir de Juiz de Fora, ecoava fortemente em todo o País. Minas era ao mesmo tempo o lócus de antigas tradições e de correntes de pensamento renovador. Belisário sabia disso, e atuava em conformidade com seu formidável senso político no sentido de buscar lá, e no Distrito Federal, o lastro para suas cruzadas pelo saneamento.

Os objetivos da Liga Pró-Saneamento, criada naquele ano de 1918, voltavam-se para o vasto interior brasileiro, ao qual muito comumente se chamava “o sertão". Na verdade, a literatura tem indicado que o "sertão" de Belisário e seus companheiros era a metáfora do Brasil, um país cuja população e ocupação eram vastamente rurais. (A população rural alcançava 85\% em 1920). Em suas falas por todo o País, nomeava as três grandes endemias que castigavam o território brasileiro e que seriam combatidas pelo esforço nacional de saneamento eram a ancilostomíase (também conhecida como opilação), a malária e a moléstia de Chagas - esta levando o nome de seu maior pesquisador.

Os debates em defesa da saúde passaram a ocupar um lugar de destaque na opinião pública e de fato resultaram em progressos significativos, 
seja no combate às endemias, seja na criação de um quadro institucional que viabilizasse as campanhas sanitárias., A década de 1910 foi o divisor de águas entre correntes de pensamento negativo (a situação racial brasileira considerada como um fardo) e positivo (a situação racial como um possível trunfo). 0 quadro que se delineará nas décadas subsequentes será mais favorável para os que, ao defenderem a "salvação nacional pela raça", apostavam na melhora da saúde dos brasileiros. Um ponto polêmico e intrigante logo se coloca para o leitor: como foi possível a Belisário e seus companheiros de tantas ligas - de Defesa Nacional, Pró-Saneamento etc. - virem a falar mais alto que os arautos da desesperança, da descrença no "aprimoramento da raça" no meio tropical?

Sem dúvida, um fator importante estava no apelo público das ideologias de mudança defendidas por Belisário. Interessante notar, em sua conferência de 1918, em Juiz de Fora, as críticas feitas à burocracia oficial e ao "desbarato dos dinheiros públicos", críticas que nos dias de hoje teriam de ser ainda mais acerbas. Havia, ali, na atuação constante do sanitarista em "santas cruzadas", uma vocação pela política e pelo apego à militância fora dos círculos estreitos do mundo médico-social (Penna, 1918b). Como tanto já se escreveu, havia naquelas ações salvadoras uma energia emocional que acabaria por contrastar vivamente com a atuação das burocracias de saúde que, a partir da criação de ministérios e agências todo poderosas, começariam, paradoxalmente, a retirar dos objetivos prescritos suas reais possibilidades de consecução, em décadas recentes. Não é preciso ao leitor familiarizar-se com os clássicos da Sociologia da Burocracia para captar o "paradoxo da rotinização" da ação de um ministério e de seus aparelhos administrativos: na condução das políticas públicas resulta frquentemente, a exemplo do que sucedeu naquela época, o distanciamento em relação à população em cujo nome tais políticas são idealizadas.

Ainda aqui não cabem ilusões. Paradoxalmente, foram as gerações anteriores à etapa de desenvolvimento institucional do setor da saúde, responsável pela criação do Ministério da Saúde, em 1953, que - poucos reconhecem isso - formataram programas de notável alcance geográfico, talvez simples em es- copo, mas eficazes no contato com a população e no efetivo alcance de contingentes hoje denominados "excluídos". O serviço pioneiro de Profilaxia Rural, criado em 1918 e dirigido por Belisário, significou a extensão de postos a regiões de todo o Brasil. Em poucos anos, à luta inicial contra a doença de Chagas, a malária e a ancilostomíase (esta campanha, por sua vez, com a cooperação da Fundação Rockefeller), somou-se o combate a outras enfermidades, como as doenças venéreas e a hanseníase. É vasta a literatura sobre esse período, a exemplo de Faria (2007). Daquela época de combate às "endemias dos sertões”, importa assinalar também que este período republicano não gerou apenas doutrinas ultramontanas, como o Integralismo, mas fomentou ideologias de mudança, como o Tenentismo, e abrigou movimentos populares impactantes, como a greve geral operária que paralisou a capital paulista em 1917. Os atores dessa época, a exemplo de nosso combatente da saúde pública, não foram meros coadjuvantes ou "colaboradores eficientes" das classes dominantes, como já se disse deles e dos ativistas da Associação Brasileira de Educação. Pelo contrário, a ABE, criada em 1924, acolhia militantes de vários campos ideológicos, relacionados às correntes de pensamento sobre a "questão da raça", a que aludimos anteriormente. Belisário foi, aliás, um participante ativo dos debates ideológicos no interior da $\mathrm{ABE}$, ressaltando o binômio da higiene e eugenia, elementos que reputava necessários à construção da nação (Carvalho, 1998; Castro Santos, 2008).

Importa reter algo mais desses tempos tumultuosos, de embate entre arraigadas tradições e ideários renovadores. Já mencionamos uma das incontáveis palestras de Belisário, no auditório da Sociedade de Medicina e Cirurgia, em Juiz de Fora. No entanto, é Pedro Nava quem lembra a preferência do eminente sanitarista por plateias "leigas" e auditórios abertos ao público. Em texto \& imagens sobre ações de saúde e saneamento naquele período inicial da república, pesquisadores da Casa de Oswaldo Cruz, em Manguinhos, mostraram a orientação dada por Belisário a seus comandados, médicos, inspetores e guardas sanitários nos postos e nas escolas rurais (Hochman e col., 2002). A orientação era não somente a prestação do serviço ambulatorial, mas a preleção sobre temas de "educação higiênica". O importante era 
conquistar auditórios repletos de jovens, de estudantes, de analfabetos, de professoras normalistas, de comerciantes, de sitiantes, de trabalhadores do eito, de famílias inteiras reunidas em praças do interior e nas fazendas para ouvir o "evangelho" da higiene contra o ancilóstomo, um arqui-inimigo de Belisário. A sensibilidade de nosso caixeiro-viajante revelavase, como lembram seus estudiosos, na cessão dos próprios espaços dos postos de profilaxia para festas cívicas e religiosas, procedimento que não somente fortalecia os laços comunitários, mas criava novos laços, desta feita entre saúde e cerimônias festivas. Já salientamos o caso das tradições fúnebres e ritos a elas associados, por sua importância como veículo de valores e atitudes coletivos. Estamos agora diante de experiências de conteúdo simbólico semelhante, ensejadas com frequência pelo sanitarista.

$$
* * * *
$$

Mas, procuremos dar a Belisário Penna a palavra final nesta breve apresentação. Se pudéssemos entrevistá-lo sobre os rumos atuais da saúde pública, teríamos algumas observações polêmicas e estimulantes. Com sua eloquência, falaria horas seguidas. Não obstante, podemos extrair trechos do diálogo que teve em sua rápida e recente visita ao Brasil. Quem o trouxe à Terra? Moacyr Scliar, o excelente escritor-sanitarista, que ademais conhecia a obra de Belisário a fundo. Quando morreu, há tão pouco tempo, encontrou Belisário no céu de cara amarrada. Aos poucos, tudo se esclareceu. Scliar escrevera sobre Oswaldo Cruz \& Carlos Chagas, mas nunca dedicou um ensaio ao mineiro de Barbacena (Scliar, 2002). "Seu livro é de 2002, você tinha tempo de sobra para outro sobre minha vida de sanitarista". Mas a mágoa passou. Scliar combinou o passeio ao Brasil, convidaram Pedro Nava (já em paz com Deus e o mundo), que declinou cordialmente, porque já marcara encontro com Fernando Sabino. E para cá vieram.

Belisário chegou primeiro a Minas e já sentiu falta da tradicionalíssima Leiteria Astória, na entrada da rua Halfeld, em Juiz de Fora. Scliar ouvia seu colega e decano com interesse e encanto. Foi para a rua Halfeld, lembrava Belisário, que seu grupo havia se deslocado, madrugada adentro, depois de memorável conferência, em uma noite fria de junho de 1918, a convite da Sociedade de Medicina e Cirurgia.

Scliar surpreendeu Belisário em transe, como se estivesse embriagado - algo que detestaria, porque considerava o alcoolismo uma praga nacional. Estava na verdade atônito. Agora Scliar lhe falava em "tecnologias de saúde", o que era isso? 0 amigo lhe passava Um olhar sobre a saúde pública, sua obra recente (Scliar, 2003). Belisário lançava bem outro olhar sobre a saúde. Lembrava a frase de Miguel Pereira, seu contemporâneo, acerca do "imenso hospital" que era o Brasil de então. (- "Esquecemos de convidar o Miguel Pereira!”). Mas Belisário não se interessava, refugiava-se em seu tempo. Scliar ponderava que a iniciativa governamental se fez presente em pouco tempo. Já no governo de Vargas, lembrava-lhe, o País tinha hospitais públicos de excelência, como o Hospital Miguel Couto no Rio de Janeiro e o das Clínicas em São Paulo - exemplos de primeira grandeza para atender à população. Eram "imensos hospitais", em um sentido rigorosamente distinto do que empregara Miguel Pereira. Foi difícil a Belisário entender o que havia ocorrido desde então, ao tomar conhecimento da brutal destruição do sistema hospitalar público no Brasil.

Frustração. Indignação. Isso calava fundo em nosso combatente. Seu guia não poderia ocultarlhe os passos em falso da Saúde Pública em nossos tempos. Contudo, não houve conquistas, em tantas décadas? Scliar levou Belisário a um imenso congresso científico, dedicado ao debate sobre a saúde nacional. Extasiado ele se confessaria agora, diante do que ouviu sobre as associações brasileiras e latino-americanas de medicina social e saúde pública, sobre as gerações atuais de profissionais e trabalhadores de saúde. (Surpreendeu-se um pouco com o neologismo "coletiva” para a saúde. "Que história é essa, Scliar?”). Os desafios da saúde em um País agora predominantemente urbano atraíam sua sensibilidade política aguçada. Em 1988, soube Belisário, o Brasil havia aprovado uma lei complementar à nova constituição, que instituíra o Sistema Único de Saúde. Previam-se novos rumos para a atenção à saúde em todo o País, que cinquenta anos antes seriam impensáveis: a saúde como direito fundamental, a universalização da assistência finalmente garantida pelo Estado, a participação da população em espaços deliberativos. A legislação do SUS era 
bem-vinda para nosso velho personagem, ele que sempre lutara pela expansão do poder central sobre as oligarquias regionais, infensas às necessidades da população, e pregara a exigência de regulamentos sanitários que ampliassem a área de atuação pública. Belisário se disse feliz - ou haveria talvez uma ponta de socrática ironia em seu comentário? - ao ouvir sobre os milhares de trabalhos científicos apresentados em congressos nacionais e regionais - muitos dedicados a debater o Sistema Único de Saúde -, sobre os incontáveis debates e publicações promovidos por centros de estudos, conselhos nacionais, observatórios de recursos humanos, laboratórios de pesquisa, seminários de projetos e estudos sobre saúde. Nunca, deduziu ele, tantos se apegaram à "santa cruzada do saneamento do Brasil". Nunca tantos escreveram sobre o tema e o debateram, nos fóruns e congressos científicos que se contam hoje às dezenas ou centenas, ano após ano, como lhe informava Scliar.

Belisário queria saber onde se revelava ("ou seria que se omitiam?”) o envolvimento dos sanitaristas com a população, ao modo dos militantes da Liga Pró-Saneamento nos anos vinte. Não resta dúvida de que Belisário era um combatente com as limitações de seu tempo e de sua origem de classe. Como tantos de sua geração aderiram ao movimento integralista, também embarcou na canoa furada, mas explicava ao Scliar - agora este é que o olhava desconfiado que o ideário antioligárquico em defesa de "valores nacionais" por certo havia atraído muita gente boa. Como morreu pouco antes de constatar as raízes visceralmente nazi-fascistas do integralismo, não teve tempo de repudiá-lo. Scliar continuava cético. No entanto, dizia nosso "caixeiro-viajante da saúde", fora o caráter mobilizador do movimento integralista que o atraíra, a comunicação com o povo, mexer com os nervos da política nas ruas, em defesa do saneamento do Brasil. Os tempos do SUS são outros, constatava Belisário com desaponto. Scliar ponderava que a antiga mobilização social pela saúde e pela instrução havia sido um movimento "pelo alto", de caráter elitista, e o contraponto de tudo isso seria um movimento de base, de caráter popular, assegurado, em cada município, pelos Conselhos de Saúde. Os Conselhos, Scliar esclarecia, são espaços de participação voluntária dos cidadãos, que assim podem acompanhar e avaliar, de modo contínuo, a evolução do SUS. Mas Belisário assistira a uma palestra sobre o SUS e os Conselhos, no congresso científico em companhia de Scliar. E haviam lhe passado um texto muito bom sobre os Conselhos de Saúde. Ninguém o iria iludir, pois agora tinha ciência de que "o despotismo burocrático, as relações clientelistas e prebendárias e o desrespeito pela res pública" (Labra, 2006, p. 218) eram as pedras no caminho desses espaços de participação popular e de seu caráter democrático.

Os novos atores haviam esquecido a lição dos velhos combatentes? A defesa da saúde teria perdido o diálogo direto de seus protagonistas com o povo nas praças e campos, no interior, nos centros de saúde, nos hospitais? Teria se engessado e distanciado a relação entre os profissionais e a população? Belisário julgava que talvez encontrasse na imprensa diária a repercussão sobre os rumos, conquistas e percalços da reforma sanitária ainda em processo, quase cem anos depois da Liga. Lembremos que Belisário Penna sempre devotou à imprensa seu justo valor e nela encontrava receptividade. As campanhas da Liga Pró-Saneamento, de alcance popular já sublinhado, repercutiam bem na imprensa.

No entanto, nova decepção do sanitarista. Scliar estava de pleno acordo. Como explicar o silêncio dos jornais sobre o ideário do SUS ou sobre seus objetivos, que lembravam tanto a luta do passado, de crença e apreço pelos cidadãos, pelos homens e mulheres humildes deste país? A imprensa somente revelava os problemas imensos na atenção à saúde. Se a imprensa livre se cala sobre as conquistas, quais os motivos do silêncio? "Onde erraram, onde erramos?", perguntava ao colega gaúcho. "Scliar, a frase profética do Miguel Pereira se aplica com muito mais razão ao imenso hospital desses doentes desassistidos, nessas filas imensas no sistema de atendimento do SUS, na desatenção, no acolhimento desumano que recebem". Scliar explicou-lhe o que era o sistema de apartheid na África do Sul, e referiuse então ao nosso "apartheid sanitário". Seria este o triste cenário para um enorme contingente de marginalizados, na dependência dos serviços precários da saúde oficial. Belisário concluiu então que lá, no sul africano, estava em curso um processo de mudança social profunda, aqui estávamos no terreno das ide- 
ologias vazias, sem participação, sem envolvimento da população.

Num último congresso, em São Paulo, ele deixara exemplares de sua obra Saneamento do Brasil (Penna, 1918) nas salas, antes do início das palestras e mesas-redondas. (Tantos exemplares esquecidos ou abandonados nas cadeiras, nosso autor constatou mais tarde). Ouvira alguém comentar que um hospital público municipal do Rio de Janeiro havia fechado as portas por falta de médicos! Belisário recordava-se que, onde se localizava este hospital, havia antes o Desinfectório de Botafogo, com suas câmaras de gás sulfuroso, seus fornos de incineração para desinfetar e purificar casas, camas, objetos infectados e roupas de enfermos contagiosos. Teorias antigas, técnicas antigas, superadas por outras teorias e "tecnologias". Mas, de que serviam à população tantas mudanças, tantas inovações? "Por que diabos não saem dos congressos e faculdades e vão direto aos hospitais públicos, aos centros de saúde, ver como se aplicam as teorias e técnicas?". "Calma, Belisário. Vamos deixar o diabo para nossos superiores”. Mas Belisário não teria razão? Vinha de uma época em que se levavam a sério os ritos de sociabilidade. Parecia-lhe que a academia se encerrara em seus espaços e se protegia com paliçadas, em total incomunicabilidade com a massa de excluídos sociais, fragilizada e desorganizada. Não bastavam teorias, era preciso chegar à população, empolgá-la, discutir e debater seus direitos. Contudo, o sanitarista mineiro excedera-se no destampatório, passara o sinal vermelho, teriam de retornar. Como tudo pode acontecer à meia noite em Paris, também tudo pode nas madrugadas do Rio de Janeiro. Nossos sanitaristas estavam na Lapa, quando delicadamente, com tapinhas nas costas, chegaram os anjos de Wim Wenders, emissários celestes. Tinham de ir embora, ordens de cima.

\section{Referências}

AROUCA, S. Entrevista: Sérgio Arouca [out. 2002]. Entrevistadores: A. B. de Noronha, C. Xavier, D. Sophia, K. Machado e R. L. Rocha. Trabalho, Educação e Saúde, v. 1, n. 2, p. 355-361, 2003. Entrevista concedida à Revista RADIS Comunicação em Saúde.
CARVALHO, M. M. C. de. Molde nacional e forma cívica: higiene, moral e trabalho no projeto da Associação Brasileira de Educação (1924-1931). Bragança Paulista: EdUSF, 1998.

CASTRO SANTOS, L. A. de. O pensamento sanitarista na Primeira República: uma ideologia de construção da nacionalidade. Dados: Revista de Ciências Sociais, Rio de Janeiro, v. 28, n. 2, p. 193-210, 1985 .

CASTRO SANTOS, L. A. de. Reabrindo o debate sobre Nagle: a educação e a saúde na historiografia brasileira. Revista Brasileira de História da Educação, São Paulo, n. 16, p. 47-62, jan./abr. 2008.

CASTRO SANTOS, L. A. de; FARIA, L. Saúde e história. São Paulo: Hucitec, 2010.

ESCOREL, S. Saúde pública: utopia de Brasil. Rio de Janeiro: Relume-Dumará, 2000.

FARIA, L. Saúde e política: a Fundação Rockefeller e seus parceiros em São Paulo. Rio de Janeiro: Fiocruz, 2007.

FIGUEIREDO, R. É. D. de. A cooperação entre Brasil e Estados Unidos no campo da saúde: o Serviço Especial de Saúde Pública e a política sanitária no governo Vargas. História, Ciências, Saúde - Manguinhos, Rio de Janeiro, v. 14, n. 4, p. 1429-1434, 2007.

HOCHMAN, G. Logo ali, no final da avenida: "Os Sertões" redefinidos pelo movimento sanitarista da Primeira República. História, Ciências, Saúde - Manguinhos, Rio de Janeiro, v. 5, p. 217-235, jul. 1998. Suplemento.

HOCHMAN, G.; BANDEIRA DE MELLO, M. T.; SANTOS, P. R. E. dos. A malária em foto: imagens de campanhas e ações no Brasil da primeira metade do século XX. História, Ciências, Saúde Manguinhos, Rio de Janeiro, v. 9, p. 233-273, jul. 2002. Suplemento.

LABRA, M. E. Conselhos de saúde: visões 'macro' e 'micro'. Civitas, Porto Alegre , v. 6, n. 1, p. 199-221, 2006.

LIMA, N. T. Um sertão chamado Brasil. Rio de Janeiro: Revam: Iuperj, 1999. 